\title{
Validation of Functional Performance Tests after Anterior Cruciate Ligament Reconstruction
}

\author{
Doo Hwan Kong, $\mathrm{MS}^{1}$, Sang Jin Yang, $\mathrm{MS}^{1}$, Jeong Ku Ha, $\mathrm{MD}^{2}$, Seok Hwan Jang, $\mathrm{MD}^{2}$, Jung Gook Seo, $\mathrm{MD}^{2}$ and \\ Jin Goo Kim, $\mathrm{MD}^{1,2}$ \\ ${ }^{1}$ Sports Medicine Research Institute, ${ }^{2}$ Department of Orthopedic Surgery, Inje University Seoul Paik Hospital, Inje University College of Medicine, Seoul, Korea
}

\begin{abstract}
Purpose: To validate the functional performance tests (FPTs) after anterior cruciate ligament (ACL) reconstruction.
Materials and Methods: Thirty men in their third decade after ACL reconstruction at 6 month follow-up and thirty healthy subjects were selected. Lysholm knee score, International Knee Documentation Committee (IKDC) subjective score, Tegner activity score, KT-2000 arthrometer test, isokinetic strength test, functional performance tests (one leg hop test, co-contraction test, shuttle run test, carioca test) were performed in two groups. We evaluated the test-retest reliability of FPTs in healthy group and the between FPTs and other parameters in ACL reconstruction group.

Results: The test-retest result showed high correlation in co-contraction test $(\mathrm{r}=0.511)$, shuttle run test $(\mathrm{r}=0.746)$, carioca test $(\mathrm{r}=0.742)$. In the ACL reconstruction group, the IKDC score, Tegner activity score, extensor power at $60 \%$, and one leg hop test also showed high correlation between each test.

Conclusions: The three FPTs showed correlations with the established methods for determining return to sports activities after ACL reconstruction and had high test-retest reliability. Therefore we believe the three FPTs can be useful methods to assess knee function in athletes after ACL reconstruction.
\end{abstract}

Key words: Anterior cruciate ligament, Reconstruction, Functional performance test.

\section{Introduction}

It is a major challenge to determine when it is safe to return to normal activities for patients in rehabilitation after anterior cruciate ligament (ACL) reconstruction ${ }^{1)}$.

The Lachman test, anterior drawer test, pivot shift test, KT-2000 arthrometer test, and isokinetic strength test have been used to determine when to resume physical activities, especially sports

Received June 7, 2011; Revised (1st) July 3, 2011; (2nd) July 30, 2011;

Accepted October 20, 2011.

Correspondence to: Jin Goo Kim, MD.

Department of Orthopedic Surgery, Inje University Seoul Paik Hospital, Inje University College of Medicine, 9 Mareunnae-ro, Jung-gu, Seoul 100-032, Korea.

Tel: +82-2-2270-0084, Fax: +82-2-2270-0085

Email: boram107@hanmail.net

This is an Open Access article distributed under the terms of the Creative Commons Attribution Non-Commercial License (http://creativecommons.org/licenses/by-nc/3.0/) which permits unrestricted non-commercial use, distribution, and reproduction in any medium, provided the original work is properly cited. activities. However, some studies have shown that these tests are not reliable predictors of the functional stability of the knee in sports activities ${ }^{2-4)}$.

To overcome the limitations of the aforementioned methods, various functional performance tests (FPTs) have been introduced including the figure-eight course run test, shuttle run test, one leg hop for distance test, and carioca test ${ }^{3,5-8)}$.

Among them, three FPTs (cocontraction test, carioca test, and shuttle run test) suggested by Lephart et al. ${ }^{3,9)}$ are delicate tests that assess knee function with regard to cocontraction with muscles associated with the ACL, pivoting, and stopping and turning. The cocontraction test reproduces rotational forces on the knee that cause tibial translation and are mostly controlled by the thigh musculature. The shuttle run test reproduces acceleration and deceleration forces that are common in sports activities. The carioca test reproduces the pivot-shift phenomenon in the ACLinsufficient knee when subjects move laterally with a cross-over step.

To use these tests for functional assessment in clinical settings, a set of criteria should be developed to differentiate normal and abnormal findings according to gender, age, and activity level. In this study, we investigated the validity of the three FPTs and 
their relationships with clinical evaluation in ACL reconstruction patients and healthy controls.

\section{Materials and Methods}

\section{Materials}

A total of 60 male subjects were enrolled in this study. The ACL reconstruction group included 30 patients in their 20 s. They underwent single bundle ACL reconstruction using a quadruple semitendinosus tendon (ST) autograft or quadruple ST and gracilis tendon autograft by the same surgeon. The FPTs were done at $\geq 6$ months postoperatively. Medial meniscal tear repair, medial menisectomy, and lateral meniscal tear repair were performed additionally in 4,1 , and 4 of the patients, respectively.

The healthy group consisted of 30 males in their 20s who were similar in terms of age and activity level. None of them underwent surgery in the lower limb or were diagnosed with an orthopedic disorder in the most recent year (Table 1).

\section{Methods}

Male patients who were in their 20s and received an ACL reconstruction (ACL reconstruction group) and healthy male subjects who were matched for age, weight, height, and activity level (healthy group) were enrolled in this study.

In both groups, the Lysholm knee score, IKDC subjective score, and Tegner activity score were measured and the KT2000 arthrometer test, isokinetic strength test (Biodex System 3 isokinetic dynamometer, Biodex Medical Systems, Shirley, Shirley, NY, USA), one leg hop test, and three FPTs (cocontraction test, shuttle run test, carioca test) were performed.

To assess the test-retest reliability of the three FPTs, the 1st and 2nd tests were performed with an interval of two weeks in the healthy group.

\section{1) KT-2000 arthrometer test}

The patient was placed in the supine position with the knee flexed to $30^{\circ}$. The arrow on the arthrometer was placed to be in line with the tibia using Velcro straps. Anterior translation at 30

Table 1. Demographic Information of the Subjects in This Study

\begin{tabular}{lcccl}
\hline Group & $\mathrm{n}$ & Age $(\mathrm{yr})$ & Height $(\mathrm{cm})$ & Weight $(\mathrm{kg})$ \\
\hline ACLR & 30 & $23.43 \pm 3.17$ & $177 \pm 7.07$ & $77.07 \pm 8.41$ \\
Healthy & 30 & $24.73 \pm 2.16$ & $174 \pm 4.58$ & $74.95 \pm 10.75$ \\
\hline
\end{tabular}

Values are presented as mean \pm standard deviation.

ACLR: anterior cruciate ligament reconstruction. lb was measured in $\mathrm{mm}$.

\section{2) Isokinetic strength test}

The isokinetic strength test was performed to measure the muscle strength of the involved and uninvolved knees. The patient was seated with the hip flexed at $90^{\circ}$. The position was maintained by securing straps at the chest, hip, and thigh. The lateral femoral condyle was aligned with the rotational axis of the dynamometer and the dynamometer arm was secured to the lower leg $2 \mathrm{~cm}$ proximal to the ankle. Measurements were performed at $60 \%$ four times for each patient. The data was categorized according to the muscle strength variables.

\section{3) One leg hop test}

The patient was asked to stand on one leg and jump as far forward as possible. This procedure was repeated three times for each leg. The longest distance of the three trials for each leg was used for analysis.

\section{4) Cocontraction test}

The cocontraction test was performed by securing a Velcro belt around the patient's waist. The belt was attached to a long rubber tube with a length of $122 \mathrm{~cm}$ (48 inches) and a diameter of 2.54 $\mathrm{cm}$ ( 1 inch). The tube was anchored to a metal loop that was secured on a wall $154 \mathrm{~cm}$ (60 inches) above the floor. A semicircle with a radius of $244 \mathrm{~cm}$ from the metal loop was painted on the floor. The patient standing with his toes on the line was asked to run wall to wall along the semicircular line five times ( 3 times, right to left and 2 times, left to right) and the time to completion was measured (Fig. 1).

\section{5) Shuttle run test}

The shuttle run test was performed by asking the patient to run

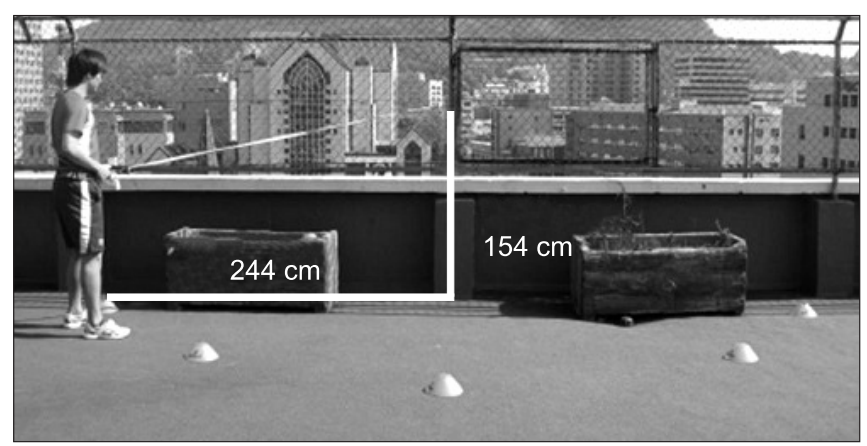

Fig. 1. Co-contraction test. The co-contraction test was performed for each subject to complete five wall-to-wall lengths of the $180^{\circ}$ semicircle by securing a heavy Velcro belt around the waist. 
back and forth on a $6.1 \mathrm{~m}$ course. The patient ran and touched a line at the end of the course and ran in reverse direction to touch the line at the starting point and repeated this process. Therefore, the test covered $24.4 \mathrm{~m}$ with three changes in direction and the fastest speed was recorded.

\section{6) Carioca test}

The carioca test was performed by requiring the patient to run laterally two lengths of a $12 \mathrm{~m}$ distance with a crossover step. The patient ran the course from left to right and then in reverse direction and the fastest speed was recorded (Fig. 2).

\section{Statistical Analysis}

The data generated in this study was analyzed using SPSS ver. 15.0 (SPSS Inc., Chicago, IL, USA). To assess the validity of the FPTs, the correlations between the three FPTs and subjective/

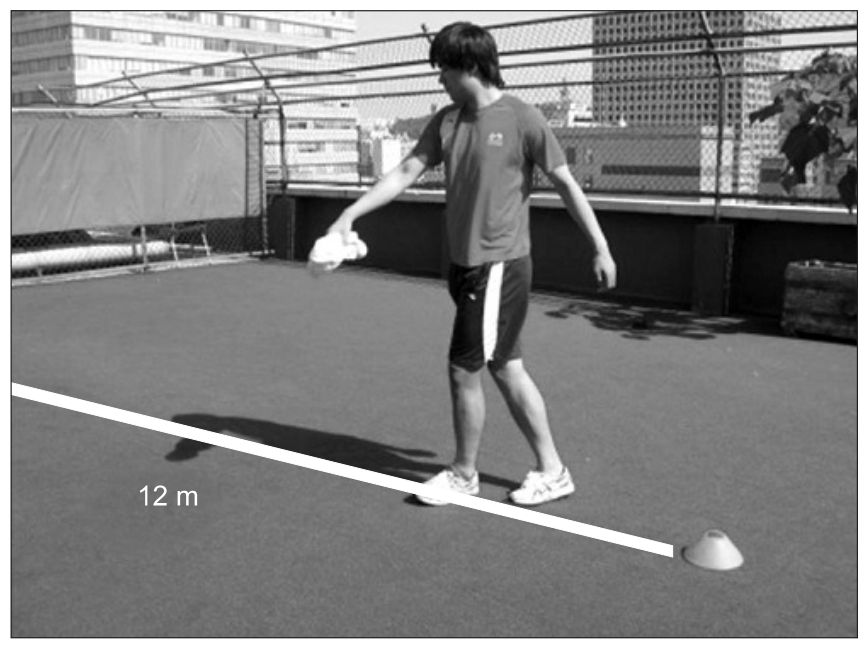

Fig. 2. Carioca test. The carioca test was performed on the subjects to move laterally with a crossover step and performed over two lengths of a 40 foot distance in as minimum an amount of time as possible. objective evaluation methods were analyzed using Pearson product-moment correlation. To assess the test-retest reliability, the FPT results obtained with an interval of two weeks were analyzed using the Pearson product-moment correlation. Statistical significance was set at $\mathrm{p}<0.05$.

\section{Results}

The test-retest reliability of the three FPTs was high: cocontraction test, $\mathrm{r}=0.511$ and $\mathrm{p}=0.025$; shuttle run test, $\mathrm{r}=0.746$ and $\mathrm{p}=0.000$; and carioca test, $\mathrm{r}=0.742$ and $\mathrm{p}=0.000$ (Table 2). The FPT results in the healthy group and ACL reconstruction group are presented in Table 3. In the ACL reconstruction group, the FPT results were significantly correlated with the IKDC subjective score, Tegner activity score, and KT-2000 arthrometer test results: 1$)$ the correlation coefficient of the cocontraction test was $\mathrm{r}=-0.569(\mathrm{p}=0.001), \mathrm{r}=-0.397(\mathrm{p}=0.030)$, and $\mathrm{r}=0.499$ $(\mathrm{p}=0.008)$, respectively; 2$)$ the value of the shuttle run test was $\mathrm{r}=-0.512(\mathrm{p}=0.004)$ and $\mathrm{r}=-0.505(\mathrm{p}=0.004)$, respectively; and 3 ) the value of the carioca test with the IKDC subjective score and Tegner activity score was $\mathrm{r}=-0.453(\mathrm{p}=0.012)$ and $\mathrm{r}=$ $-0.484(\mathrm{p}=0.007)$, respectively (Table 4$)$. Statistically significant correlations were also observed between the three FPTs and all the isokinetic strength test variables including the extensor peak torque at $60 \%$, peak torque per body weight, total work, and total work per body weight of the involved knee (Table 5). The FPTs were positively correlated with the one leg hop test: 1) the correlation coefficient of the cocontraction test in the involved knee and the uninvolved knee was $\mathrm{r}=-0.701(\mathrm{p}=0.000)$ and $\mathrm{r}=$ -0.745 ( $\mathrm{p}=0.000$ ), respectively; 2 ) the value of the shuttle run test was $\mathrm{r}=-0.756(\mathrm{p}=0.000)$ and $\mathrm{r}=-0.747(\mathrm{p}=0.000)$, respectively; and 3) the value of the carioca test was $r=-0.749(\mathrm{p}=0.000)$ and $\mathrm{r}=-0.596(\mathrm{p}=0.000)$, respectively (Table 6). There were significant relationships among the three FPTs: 1) the correlation coefficient

Table 2. Test-Retest on Three FPTs in the Healthy Group

\begin{tabular}{llcc}
\hline \multirow{2}{*}{ 1st test } & & \multicolumn{2}{c}{ 2nd test } \\
\cline { 3 - 4 } Co-contraction test (sec) & Correlation coefficient & Co-contraction & Shuttle run test \\
Shuttle run test (sec) & p-value & $0.511^{\mathrm{a})}$ & 0.025 \\
& Correlation coefficient & & $0.746^{\text {b) }}$ \\
Carioca test (sec) & p-value & Correlation coefficient & 0.000 \\
& p-value & & $0.742^{\text {b) }}$ \\
\hline
\end{tabular}

FPTs: functional performance test.

a) $<0.05,{ }^{\text {b) }}$ p $<0.01$. 
Table 3. The Results of the Three FPTs between the Two Groups

\begin{tabular}{|c|c|c|c|c|c|c|c|c|}
\hline & \multicolumn{4}{|c|}{ Healthy group } & \multicolumn{4}{|c|}{ ACL reconstruction group } \\
\hline & Minimum value & Maximum value & Mean & SD & Minimum value & Maximum value & Mean & SD \\
\hline Co-contraction (sec) & 11.59 & 15.84 & 13.3 & 1.04 & 11.47 & 27.09 & 14.89 & 2.91 \\
\hline Shuttle run test (sec) & 5.73 & 7.31 & 6.49 & 0.39 & 6.02 & 10.39 & 7.67 & 0.97 \\
\hline Carioca test (sec) & 5.78 & 9.31 & 6.96 & 0.81 & 5.50 & 16.16 & 9.31 & 2.43 \\
\hline
\end{tabular}

FPTs: functional performance test, ACL: anterior cruciate ligament, SD: standard deviation.

Table 4. Correlation between the Three FPTs, Subjective Scores and KT-2000 in the ACL Reconstruction Group

\begin{tabular}{|c|c|c|c|c|c|}
\hline & & Lysholm score & IKDC score & Tegner score & KT-2000 deficits \\
\hline \multirow[t]{2}{*}{ Co-contraction test } & Correlation coefficient & -0.057 & $-0.569^{\mathrm{a})}$ & $-0.397^{\mathrm{b})}$ & $0.499^{\mathrm{a})}$ \\
\hline & $\mathrm{p}$-value & 0.763 & 0.001 & 0.030 & 0.008 \\
\hline \multirow[t]{2}{*}{ Shuttle run test } & Correlation coefficient & -0.191 & $-0.512^{\mathrm{a})}$ & $-0.505^{\mathrm{a})}$ & 0.268 \\
\hline & $\mathrm{p}$-value & 0.312 & 0.004 & 0.004 & 0.177 \\
\hline \multirow[t]{2}{*}{ Carioca test } & Correlation coefficient & -0.058 & $-0.453^{\mathrm{b})}$ & $-0.484^{\mathrm{a})}$ & 0.297 \\
\hline & $\mathrm{p}$-value & 0.761 & 0.012 & 0.007 & 0.132 \\
\hline
\end{tabular}

FPTs: functional performance test, ACL: anterior cruciate ligament, IKDC: International Knee Documentation Committee. ${ }^{\mathrm{a})} \mathrm{p}<0.01,{ }^{\text {b) }} \mathrm{p}<0.05$.

Table 5. Correlation between the Three FPTs and Isokinetic Strength Test in the ACL Reconstruction Group

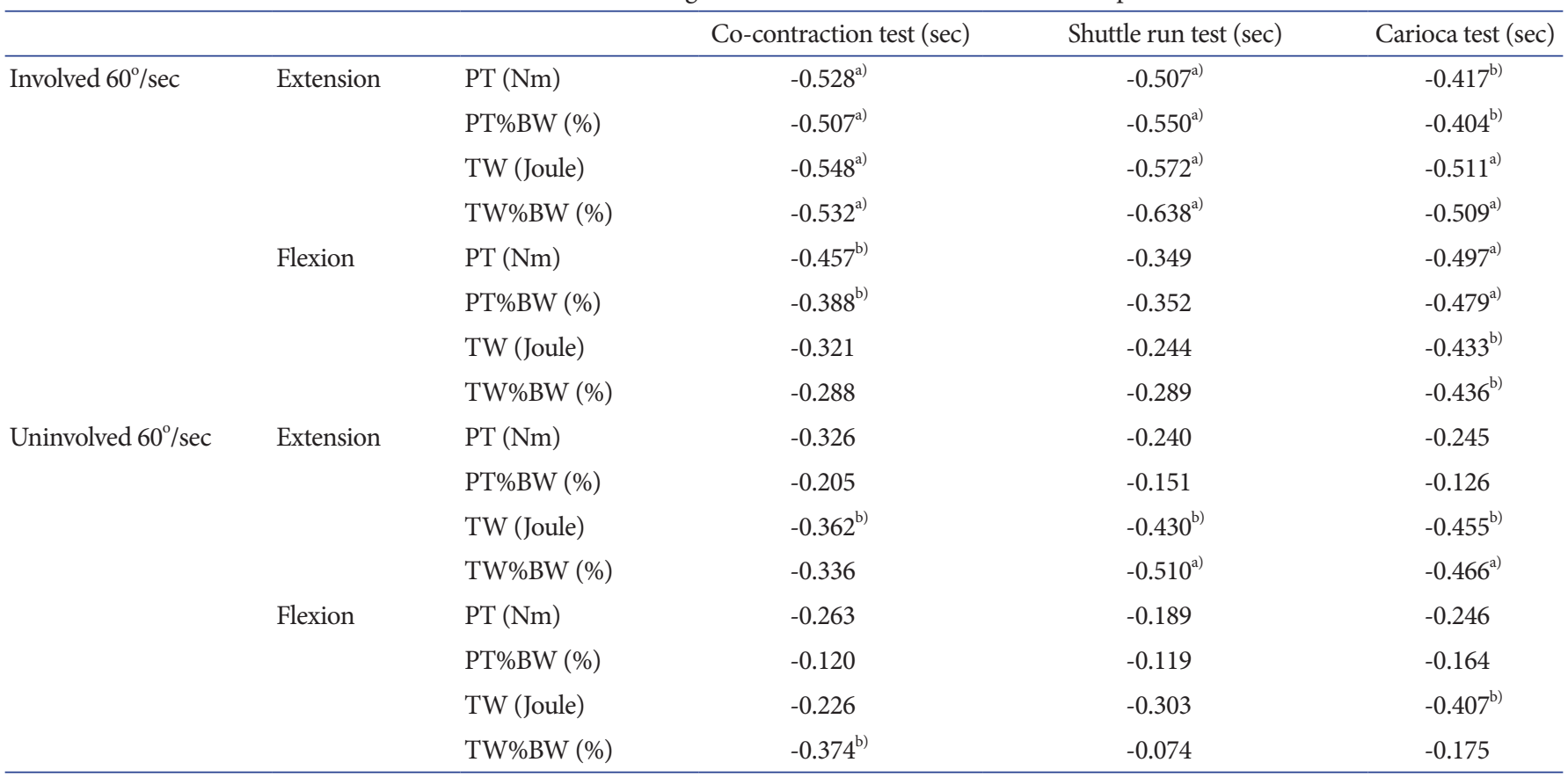

FPTs: functional performance test, ACL: anterior cruciate ligament, PT: peak torque, BW: body weight, TW: total work.

a) $\mathrm{p}<0.01,{ }^{\text {b) }} \mathrm{p}<0.05$.

of the cocontraction test with the shuttle run test and the carioca test was $\mathrm{r}=0.730(\mathrm{p}=0.000)$ and $\mathrm{r}=0.709(\mathrm{p}=0.000)$, respectively; and 2) the value of the shuttle run test with the carioca test was $\mathrm{r}=0.711(\mathrm{p}=0.000)$ (Table 7).

\section{Discussion}

The purpose of this study was to investigate whether the three FPTs could serve as important predictors/indicators of 
Table 6. Correlation between the Three FPTs and the One Leg Hop Test in the ACL Reconstruction Group

\begin{tabular}{|c|c|c|c|}
\hline & & Involved one hop test $(\mathrm{cm})$ & Uninvolved one hop test $(\mathrm{cm})$ \\
\hline \multirow[t]{2}{*}{ Co-contraction test (sec) } & Correlation coefficient & $-0.701^{\text {a) }}$ & $-0.745^{\text {a) }}$ \\
\hline & $\mathrm{p}$-value & 0.000 & 0.000 \\
\hline \multirow[t]{2}{*}{ Shuttle run test (sec) } & Correlation coefficient & $-0.756^{a)}$ & $-0.747^{\mathrm{a})}$ \\
\hline & p-value & 0.000 & 0.000 \\
\hline \multirow[t]{2}{*}{ Carioca test (sec) } & Correlation coefficient & $-0.749^{\mathrm{a})}$ & $-0.596^{\mathrm{a})}$ \\
\hline & $\mathrm{p}$-value & 0.000 & 0.001 \\
\hline
\end{tabular}

FPTs: functional performance test, ACL: anterior cruciate ligament. ${ }^{\mathrm{a})} \mathrm{p}<0.01$.

Table 7. Correlation of the Three FPTs in the ACL Reconstruction Group

\begin{tabular}{llll}
\hline & & Co-contraction test $(\mathrm{sec})$ & Shuttle run test (sec) \\
\hline Co-contraction test & Correlation coefficient & & \\
& p-value & & \\
Shuttle run test & Correlation coefficient & $0.730^{\mathrm{a})}$ & \\
& p-value & 0.000 & $0.711^{\mathrm{a})}$ \\
Carioca test & Correlation coefficient & $0.709^{\mathrm{a})}$ & 0.000 \\
& p-value & 0.000 & \\
\hline
\end{tabular}

FPTs: functional performance test, ACL: anterior cruciate ligament. ${ }^{\mathrm{a})} \mathrm{p}<0.01$.

knee function after ACL reconstruction. For this purpose, we evaluated correlations between the three FPTs and the subjective/ objective evaluation methods in patients at 6 months after ACL reconstruction. In addition, we assessed the test-retest reliability of the FPTs in healthy controls.

In the absence of standardized methods to assess knee function and stability after ACL reconstruction, especially for return to sports activities, surgeons previously relied on the static laxity test ${ }^{4,10)}$, physical indicators including the thigh muscle circumference and range of motion ${ }^{11)}$, and the thigh muscle peak torque $^{10,12)}$.

However, conclusive correlations have not been established between knee function and muscle strength, ligament laxity, and range of motion. This is partly due to the fact that the reliability of joint laxity measurements could be compromised due to manual measurement errors and thigh muscle strength measurement techniques have limited accuracy. In addition, subjective evaluation methods that are reliant on the patient's selfassessment for the definition of function of the ACL insufficient knee have low sensitivity and are thus inappropriate to be a criterion for assessment ${ }^{3}$.

Therefore, a determination on return to sports activities in ACL insufficient athletes should be based not on the peak torque, joint laxity, circumferential thigh girth, and range of motion but on the three FPT results ${ }^{3)}$.

Lephart et al. ${ }^{3)}$ suggested that the amount of static laxity was not related to the capacity to dynamically compensate for the ACL insufficiency because notable anterior translation of the involved knee affected neither the FPT results nor the performance of the athletes. In addition, objective test results could not necessarily be associated with subjective symptoms or joint function ${ }^{9)}$. In this study, a notable correlation with the KT-2000 arthrometer test that shows the amount of anterior translation could only be found in the cocontraction test $(\mathrm{r}=0.499)$ excluding the two remaining FPTs.

Lephart et al. ${ }^{3)}$ reported that the isokinetic strength test alone cannot appropriately evaluate the patient's ability to return to sports because peak torque has no direct association with functional performance. Anderson et al. ${ }^{2)}$ reported that the isokinetic strength test was not related to dash time, vertical jump, and agility run time test. On the other hand, some authors associated the isokinetic strength test with running, cutting, and one legged hopping ${ }^{13,14)}$ while others related the test to one legged hopping only ${ }^{15}$. Likewise, there is no consensus on the efficacy of the isokinetic strength test for functional performance assessment after ACL reconstruction. In this study, we noted a 
statistically significant relationship between the three FPTs and all variables of the isokinetic strength test of the knee extensor at $60 \%$ s.

Barber et al. ${ }^{16)}$ reported that the single leg hop test and single leg vertical jump test are more reliable tools than the isokinetic strength test for assessing functional recovery after ACL reconstruction. In this study, we also found significant correlations between the three FPTs and the one leg hop test in both the uninvolved and the involved knees. Therefore, we believe the three FPTs are useful methods for evaluation of knee joint function after ACL reconstruction.

In addition, we investigated relationships among the three FPTs by reproducing rotatory force, tibial subluxation, deceleration and acceleration that can occur during sports in patients with ACL reconstruction ${ }^{3)}$ and confirmed statistically significant correlations among them. The test-retest reliability was high in the healthy controls. It is our understanding that the three FPTs can be helpful in evaluating knee joint function and used in addition to other evaluation methods when knee joint stability is obtained through rehabilitation after ACL reconstruction.

\section{Conclusion}

The three FPTs showed correlations with the established methods for determining return to sports activities after ACL reconstruction and had high test-retest reliability. Therefore, we believe the three FPTs can be useful methods to assess knee function in athletes after ACL reconstruction.

\section{References}

1. Gustavsson A, Neeter C, Thomee P, Silbernagel KG, Augustsson J, Thomee R, Karlsson J. A test battery for evaluating hop performance in patients with an ACL injury and patients who have undergone ACL reconstruction. Knee Surg Sports Traumatol Arthrosc. 2006;14:778-88.

2. Anderson MA, Gieck JH, Perrin DH, Weltman A, Rutt RA, Denegar CR. The relationships among isometric, isotonic, and isokinetic concentric and eccentric quadriceps and hamstring force and three components of athletic performance. J Orthop Sports Phys Ther. 1991;14:114-20.

3. Lephart SM, Perrin DH, Fu FH, Gieck JH, McCue FC, Irrgang JJ. Relationship between selected physical characteristics and functional capacity in the anterior cruciate ligament-insufficient athlete. J Orthop Sports Phys
Ther. 1992;16:174-81.

4. Wilk KE, Romaniello WT, Soscia SM, Arrigo CA, Andrews JR. The relationship between subjective knee scores, isokinetic testing, and functional testing in the ACLreconstructed knee. J Orthop Sports Phys Ther. 1994;20:6073.

5. Keays SL, Bullock-Saxton J, Keays AC. Strength and function before and after anterior cruciate ligament reconstruction. Clin Orthop Relat Res. 2000;(373):174-83.

6. Tegner Y, Lysholm J. Rating systems in the evaluation of knee ligament injuries. Clin Orthop Relat Res. 1985;(198):43-9.

7. Tegner Y, Lysholm J, Lysholm M, Gillquist J. A performance test to monitor rehabilitation and evaluate anterior cruciate ligament injuries. Am J Sports Med. 1986;14:156-9.

8. Tibone JE, Antich TJ, Fanton GS, Moynes DR, Perry J. Functional analysis of anterior cruciate ligament instability. Am J Sports Med. 1986;14:276-84.

9. Lephart SM, Kocher MS, Harner CD, Fu FH. Quadriceps strength and functional capacity after anterior cruciate ligament reconstruction. Patellar tendon autograft versus allograft. Am J Sports Med. 1993;21:738-43.

10. Giove TP, Miller SJ 3rd, Kent BE, Sanford TL, Garrick JG. Non-operative treatment of the torn anterior cruciate ligament. J Bone Joint Surg Am. 1983;65:184-92.

11. Andrews J. Diagnosis and treatment of the ACL deficient knee. Paper presented at Mid-Atlantic National Athletic Trainers' annual meeting; 1987 May; Greensboro, NC: 1987.

12. Walla DJ, Albright JP, McAuley E, Martin RK, Eldridge V, El-Khoury G. Hamstring control and the unstable anterior cruciate ligament-deficient knee. Am J Sports Med. 1985;13:34-9.

13. Barber SD, Noyes FR, Mangine RE, McCloskey JW, Hartman W. Quantitative assessment of functional limitations in normal and anterior cruciate ligament-deficient knees. Clin Orthop Relat Res. 1990;(255):204-14.

14. Karlsson J, Lundin O, Lossing IW, Peterson L. Partial rupture of the patellar ligament. Results after operative treatment. Am J Sports Med. 1991;19:403-8.

15. Jarvela T, Kannus P, Latvala K, Jarvinen M. Simple measurements in assessing muscle performance after an ACL reconstruction. Int J Sports Med. 2002;23:196-201.

16. Barber SD, Noyes FR, Mangine R, DeMaio M. Rehabilitation after ACL reconstruction: function testing. Orthopedics. 1992;15:969-74. 